\title{
SYNTHESIS AND CHARACTERIZATION OF Ni-Fe-S MAGNETIC THIN FILMS AT DIFFERENT BATH TEMPERATURES
}

\author{
M. Kanakaraj 1,* and H. B. Ramalingam ${ }^{2}$ \\ ${ }^{1}$ Department of Physics, Government Arts College, Udumalpet-642126, Tamil Nadu, India \\ ${ }^{2}$ Department of Physics, Government Arts College, Udumalpet-642126, Tamil Nadu, India \\ * E-mail: kanagarajbu@gmail.com
}

\begin{abstract}
Electrodeposited alloy thin films Ni-Fe-S were prepared at temperatures $30,50,70$ and $90^{\circ} \mathrm{C}$. Electrodeposited Ni-Fe$\mathrm{S}$ thin films were subjected to morphological, structural, magnetic and mechanical characterization analysis. The chemical composition of the coated films was analyzed by EDAX and result shows that nickel content increases when bath temperature is increased. The surface and structural morphology of the coated film were analyzed by using SEM and XRD. The results show that thin films are bright, crack free and uniform. The mechanical characterization of NiFe-S thin films have been analyzed by VHT and result shows that hardness increases when bath temperature is increased. The electroplated Ni-Fe-S thin films were strongly adherent to the copper substrate. All the electrodeposited $\mathrm{Ni}-\mathrm{Fe}-\mathrm{S}$ films exhibit FCC crystalline structure by XRD study.The VSM result of Ni-Fe-S thin films shows that thin films coated at high bath temperature have highest saturation magnetization value.

Keywords: Thin films, Characterization, Electrodeposition, Crystalline size, Temperature, X-ray diffraction, Microhardness, Surface morphology.
\end{abstract}

(C) RASĀYAN. All rights reserved

\section{INTRODUCTION}

Thin film technology is the foundation of all the astounding improvements made in solid state electronics. Electroplated $\mathrm{Ni}-\mathrm{Fe}$ is one of the most widely used materials in the fabrication of micromachines such as microcantilevers, micro gears, and their components. ${ }^{1-5}$ Electrochemical deposition or electrodeposition is one of the most suitable techniques employed in the preparation of thin films on the surface of conducting substrate. $\mathrm{NiFe}, \mathrm{NiCo}$, and $\mathrm{NiW}$ are most commonly used magnetic thin film materials in MEMS and NEMS. ${ }^{1-3,6-9} \mathrm{NiFe}$ soft magnetic thin films with low coercive force and high permeability have been widely applied in the electromagnetic wave absorbing field. The electroplated thin films of $\mathrm{Ni}, \mathrm{Co}, \mathrm{Fe}$ metals have been developed by their potential applications in NEMS and MEMS.,10-12 The performance of NiFe soft film can be enhanced by adding stress reducing agent sulfur with $\mathrm{NiFe}$ alloy. In this current investigation, the electrodeposition method has been chosen for coating Ni-Fe-S thin films. This paper summarizes the preparation technique and characterization of electroplated Ni-Fe-S magnetic films.

\section{EXPERIMENTAL}

The different working conditions and bath composition of the Ni-Fe-S thin film are shown in Table-1.The $\mathrm{Ni}-\mathrm{Fe}-\mathrm{S}$ thin films were successfully coated by electrochemical deposition method at various bath temperatures such as $30,50,70$ and $90^{\circ} \mathrm{C}$. The steel and copper substrates were used as anode and cathode respectively with the dimension of $7.5 \times 1.5 \mathrm{~cm}$. The cathode (copper substrate) was totally shielded with an adhesive tape except for the deposition area. ${ }^{13-15,18}$ Before electrodeposition process, both anode and cathode substrates were polished and cleaned in $\mathrm{NaOH}$ solution. Then they were washed with distilled water and dried in air. ${ }^{16,17,19-21}$ The bath was maintained at $6 \mathrm{pH}$ value. The films were coated on the cathode surface at various temperatures from $30^{\circ} \mathrm{C}$ to $90^{\circ} \mathrm{C}$. All the Ni-Fe-S thin films were coated at a constant current density of $3 \mathrm{~mA} / \mathrm{cm}^{2}$ and constant deposition time of 15 minutes. The cathode was carefully removed from the bath after 15 minutes and dried for few minutes. The surface morphology of Ni-Fe-S alloy films 
was investigated with the help of Scanning Electron Microscope (SEM). The film composition and structural characters of thin films were measured by Energy Dispersive X-ray Analyser (EDAX) and X-ray diffraction (XRD) respectively. ${ }^{22-25}$ Also, the hardness of Ni-Fe-S thin films was measured by Vickers Hardness Tester (VHT).The magnetic property of Ni-Fe-S thin film was measured by Vibrating Sample Magnetometer (VSM).

Table-1: Electroplating bath details of Ni-Fe-S thin films

\begin{tabular}{l|l|l|l|l|l}
\hline S. No. & Name of the chemicals & $(\mathrm{g} / \mathrm{L})$ & $\begin{array}{c}\text { Temperature } \\
\left({ }^{\circ} \mathrm{C}\right)\end{array}$ & $\begin{array}{l}\text { Current } \\
\text { Density }\end{array}$ & $\mathrm{pH}$ \\
\hline 1 & Ferrous Sulphate & 10 & \multirow{2}{*}{$30,50,70,90$} & $3 \mathrm{~mA} / \mathrm{cm}^{2}$ & 6 \\
\cline { 1 - 2 } 2 & Nickel Sulphate & 30 & & & \\
\cline { 1 - 3 } 3 & Thiourea & 15 & & & \\
\cline { 1 - 3 } 5 & Ammonium Sulphate & 40 & & & \\
\cline { 1 - 3 } & Citric acid & 10 & & & \\
\hline
\end{tabular}

\section{Composition of Electrodeposited Thin Films}

RESULTS AND DISCUSSION

The chemical composition of the electroplated thin films was analyzed by EDAX spectrum. The EDAX data of thin films are shown in Table-2. The EDAX result shows that thin films prepared at higher temperature have less percentage of sulfur content. The highest ferrous content of $16.41 \mathrm{wt} \%$ is obtained at the temperature of $50^{\circ} \mathrm{C}$. From EDAX data's, it is concluded that Nickel content increases by increasing the bath temperature. At bath temperature $90^{\circ} \mathrm{C}$, maximum Ni content of $76.36 \mathrm{wt} \%$ is obtained for Ni-Fe$\mathrm{S}$ thin films. When bath temperature is increased, the weight percentage of sulfur decreases.

Table-2: Chemical composition of Ni-Fe-S thin films (EDAX)

\begin{tabular}{c|c|c|c|c}
\hline S. No. & Temperature & $\mathrm{Fe}(\% \mathrm{Wt})$ & $\mathrm{Ni}(\% \mathrm{Wt})$ & $\mathrm{S}(\% \mathrm{Wt})$ \\
\hline 1. & $30^{\circ} \mathrm{C}$ & 13.86 & 61.38 & 24.76 \\
\hline 2 & $50^{\circ} \mathrm{C}$ & 16.41 & 63.10 & 20.49 \\
\hline 3 & $70^{\circ} \mathrm{C}$ & 12.28 & 72.06 & 15.66 \\
\hline 4 & $90^{\circ} \mathrm{C}$ & 11.36 & 76.36 & 12.28 \\
\hline
\end{tabular}

\section{Morphological Observation}

Figure-1 shows surface morphology of the electroplated Ni-Fe-S thin films with different temperatures (30, 50,70 and $90^{\circ} \mathrm{C}$ ) and thin films are smooth and uniform. They are bright and crack free. Based on SEM analysis, it is concluded that formation of Ni-Fe-S thin films on a copper substrate is uniform in nature.

\section{Structural Analysis}

Figure- 2 shows the XRD results of the deposits obtained at temperatures $30^{\circ} \mathrm{C}, 50^{\circ} \mathrm{C}, 70^{\circ} \mathrm{C}$ and $90^{\circ} \mathrm{C}$. The occurrence of sharp peaks in XRD pattern of Ni-Fe-S thin films shows that the deposits are in crystalline nature. The size of crystals in deposits is calculated by the formula:

$$
\mathrm{D}=0.954 \lambda / \beta \cos \theta
$$

Where $\theta$ is the Bragg's angle, $\lambda$ is the wavelength of X-rays, $\beta$ is FWHM of the diffraction peak at $2 \theta$. XRD results of Ni-Fe-S films reveal the presence of FCC phase with (111), (200) and (220) diffraction peaks. The result shows that the crystal sizes of thin film deposits obtained by electrochemical deposition process are in nanoscale and average crystal size is around $26 \mathrm{~nm}$. 
RASĀYAN J. Chem.

Vol. 10 | No. 3 |744 - 750 | July - September | 2017

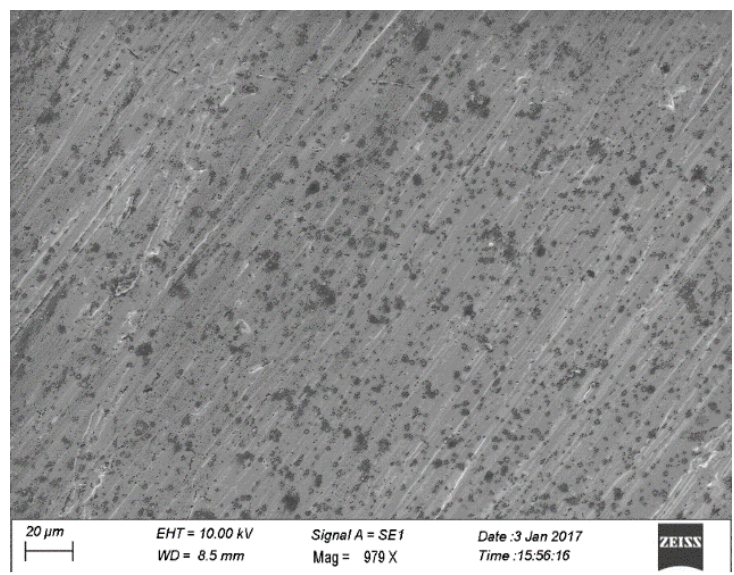

(a)

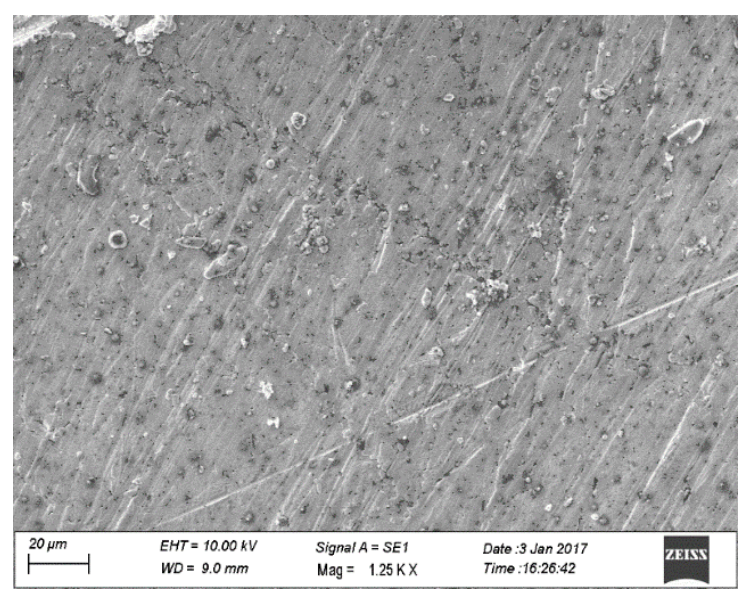

(c)

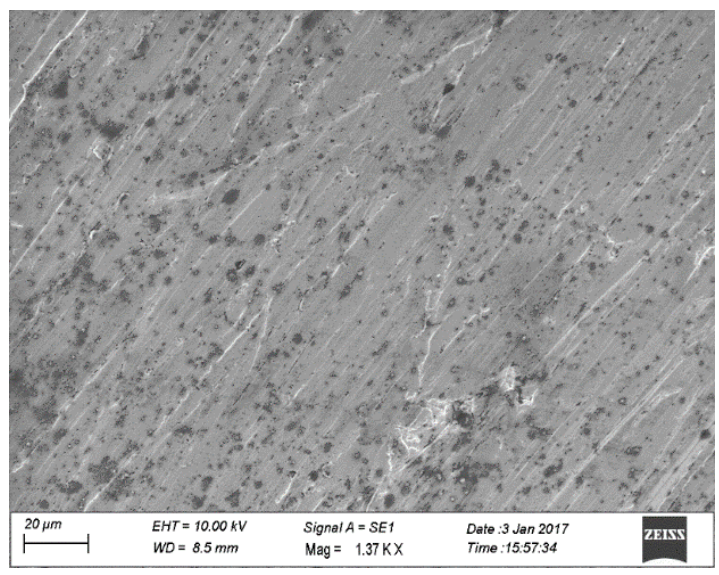

(b)

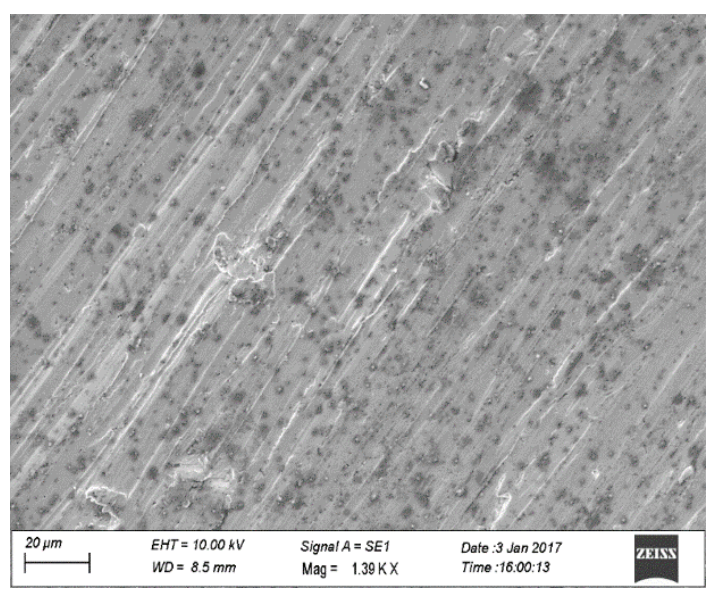

(d)

Fig.-1: Surface images (SEM) of Ni-Fe-S thin films at different bath temperatures (a) $30^{\circ} \mathrm{C}$ (b) $50^{\circ} \mathrm{C}$ (c) $70^{\circ} \mathrm{C}$ (d) $90^{\circ} \mathrm{C}$

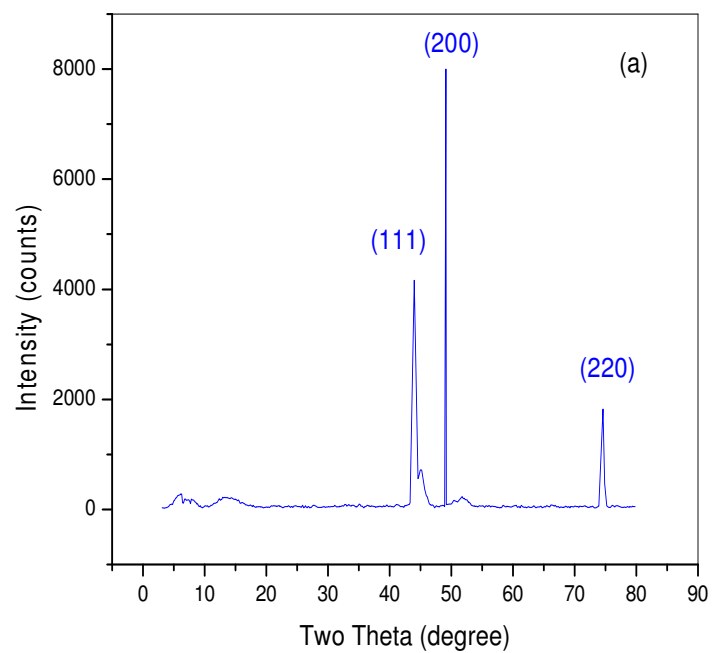

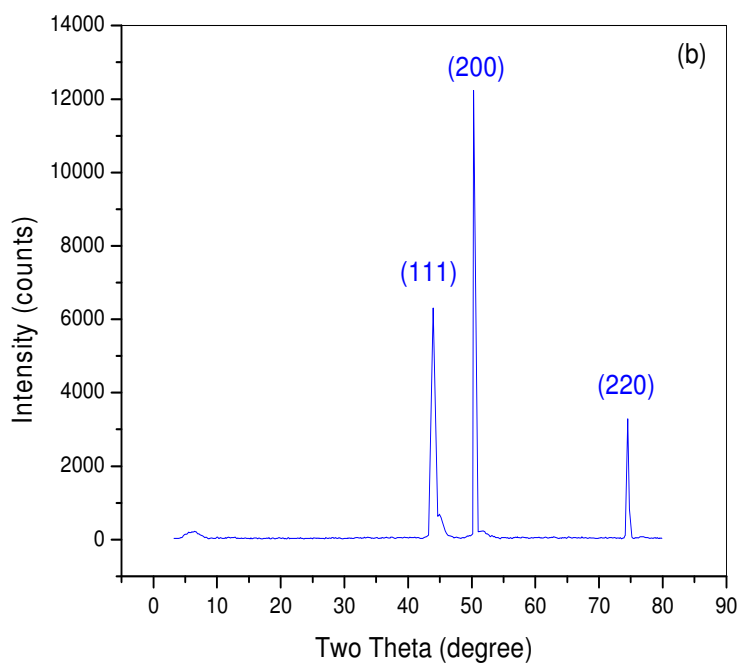

(b)

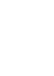


RASĀYAN J. Chem.

Vol. 10 | No. 3 |744 - 750 | July - September | 2017
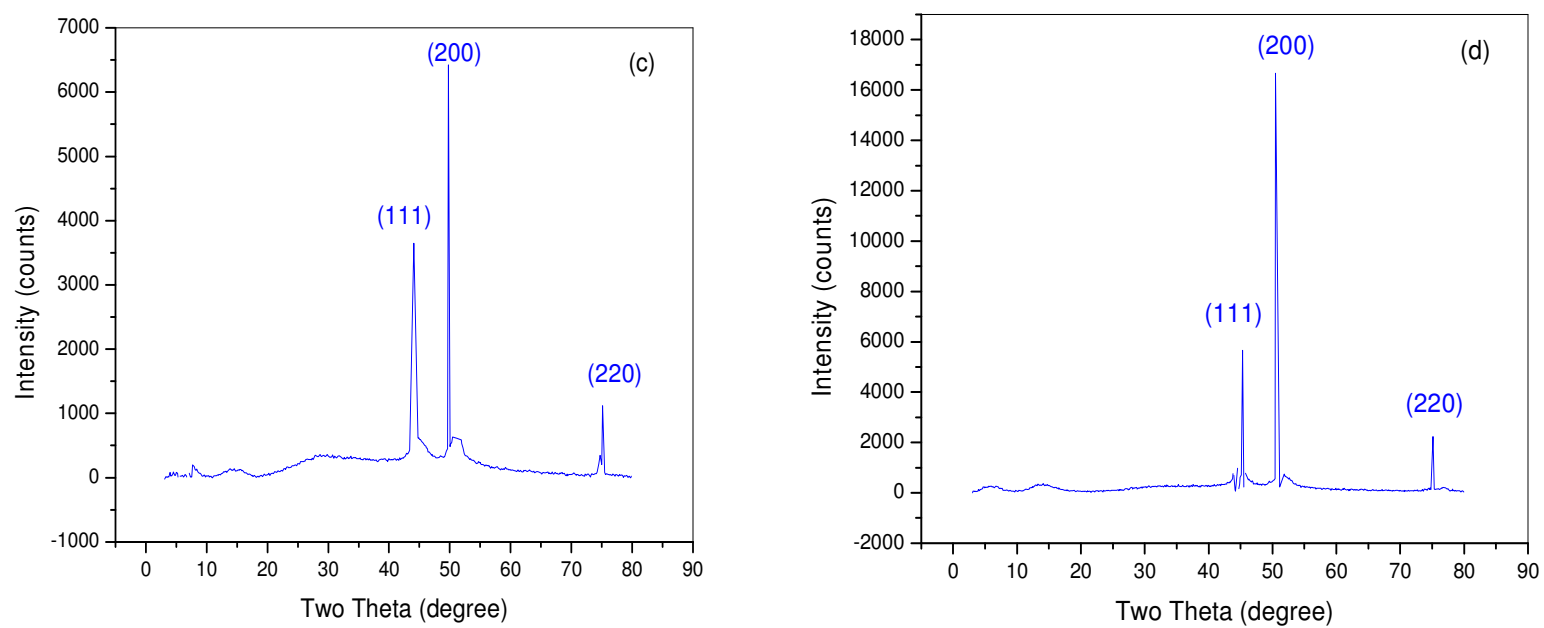

Fig.-2: XRD patterns of Ni-Fe-S thin films at (a) $30^{\circ} \mathrm{C}$ (b) $50^{\circ} \mathrm{C}$ (c) $70^{\circ} \mathrm{C}$ (d) $90^{\circ} \mathrm{C}$

The crystal sizes of Ni-Fe-S alloy films are shown in Table-3. When bath temperature is increased, crystalline size of thin films decreases due to onset orientation of crystals during electrodeposition.

Table-3: Structural characteristics of Ni-Fe-S alloy thin films

\begin{tabular}{c|c|c|c|c|c|c}
\hline S. No. & $\begin{array}{c}\text { Bath Temperature } \\
\left({ }^{\circ} \mathrm{C}\right)\end{array}$ & $\begin{array}{c}2 \theta \\
(\mathrm{deg})\end{array}$ & $\begin{array}{c}\mathrm{d} \\
\left(\mathrm{A}^{0}\right)\end{array}$ & $\begin{array}{c}\text { Particle Size(D) } \\
(\mathrm{nm})\end{array}$ & $\begin{array}{c}\text { Strain } \\
\left(10^{-3}\right)\end{array}$ & $\begin{array}{c}\text { Dislocation } \\
\text { Density } \\
\left(10^{14} / \mathrm{m}^{2}\right)\end{array}$ \\
\hline 1 & 30 & 49.16 & 1.8081 & 32.17 & 1.1254 & 09.66 \\
\hline 2 & 50 & 50.32 & 1.8211 & 29.87 & 1.2121 & 11.21 \\
\hline 3 & 70 & 49.71 & 1.8133 & 23.19 & 1.5612 & 18.60 \\
\hline 4 & 90 & 50.58 & 1.7652 & 19.34 & 1.8720 & 26.74 \\
\hline
\end{tabular}

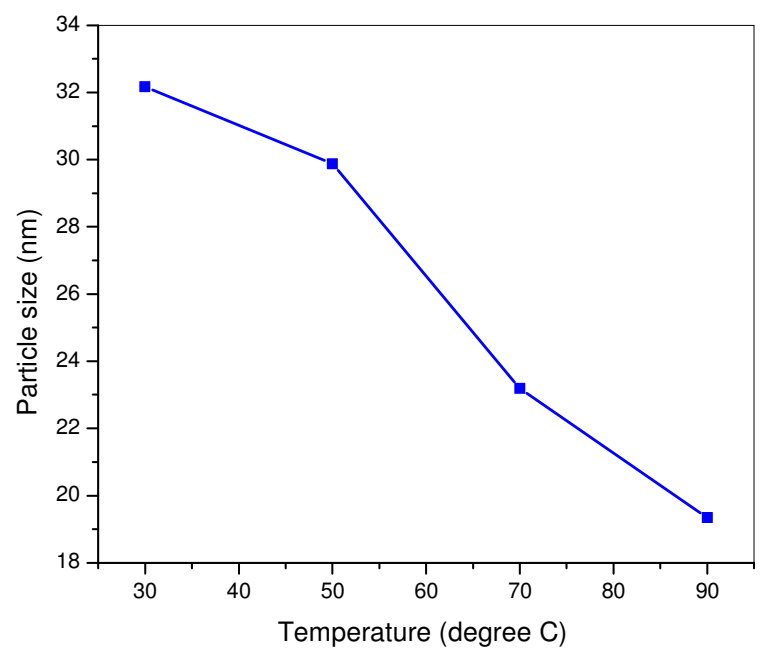

Fig.-3: Crystal size Vs Bath temperature 


\section{Mechanical Properties}

Hardness is an important mechanical property of thin films. Vickers hardness tester is used to investigate hardness properties of thin films. VHT results show that the hardness of Ni-Fe-S increases when bath temperature is increased. Hardness increases due to the involvement of lower stress during formation of $\mathrm{Ni}$ Fe-S films. The hardness of Ni-Fe-S alloy thin films is shown in Table-4.

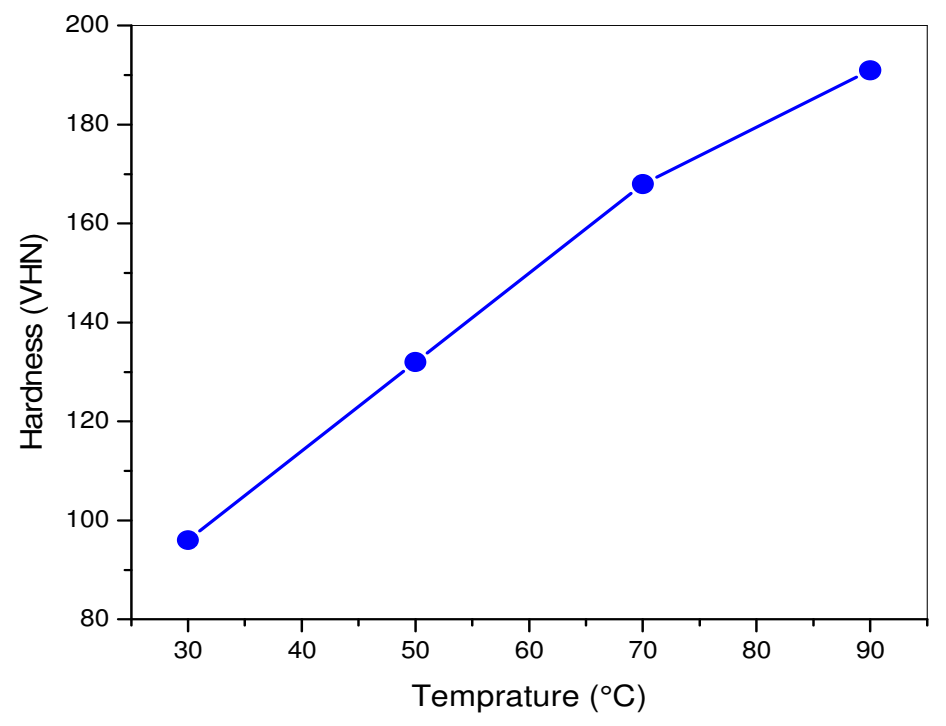

Fig.-4: Vickers Hardness Vs Bath temperature

Table-4: Hardness of Ni-Fe-S alloy thin films

\begin{tabular}{c|c|c}
\hline S. No. & Bath Temperature $\left({ }^{\circ} \mathrm{C}\right)$ & Vickers Hardness(VHN) \\
\hline 1 & 30 & 96 \\
\hline 2 & 50 & 132 \\
\hline 3 & 70 & 168 \\
\hline 4 & 90 & 191 \\
\hline
\end{tabular}

\section{Magnetic Properties of the Deposits}

Magnetic properties of Ni-Fe-S films were observed by Vibrating Sample Magnetometer (VSM) and data's are shown in Table-5.The magnetic hysteresis curves of Ni-Fe-S thin films at different temperatures are shown in Figure-6.

\begin{tabular}{c|c|c|c|c|c}
\multicolumn{7}{|c}{ Table-5: Soft Magnetic Properties of Ni-Fe-S deposits } \\
\hline S. No. & $\begin{array}{c}\text { Bath } \\
\text { Temperature } \\
\left({ }^{\circ} \mathrm{C}\right)\end{array}$ & $\begin{array}{c}\text { Coercivity } \\
\mathrm{H}_{\mathrm{s}} \\
(\mathrm{G})\end{array}$ & $\begin{array}{c}\text { Magnetization } \\
\mathrm{M}_{\mathrm{s}} \\
\left(\mathrm{emu} / \mathrm{cm}^{2}\right) \\
10^{-3}\end{array}$ & $\begin{array}{c}\text { Retentivity } \\
\mathrm{M}_{\mathrm{r}} \\
\left(\mathrm{emu} / \mathrm{cm}^{2}\right) \\
10^{-3}\end{array}$ & $\begin{array}{c}\text { Squareness } \\
\mathrm{S}_{\left(\mathrm{M}_{\mathrm{r}} / \mathrm{M}_{\mathrm{s}}\right)}\end{array}$ \\
\hline 1 & 30 & 241.32 & 7.327 & 5.7481 & 0.7845 \\
\hline 2 & 50 & 334.26 & 13.623 & 3.2731 & 0.2402 \\
\hline 3 & 70 & 352.73 & 77.271 & 32.725 & 0.4235 \\
\hline 4 & 90 & 478.12 & 136.25 & 26.923 & 0.1976 \\
\hline
\end{tabular}

Thin film coated at $90^{\circ} \mathrm{c}$ of temperature reveals higher magnetization. It is observed that the magnetization increases from $7.327 \times \mathbf{1 0}-3 \mathrm{emu} / \mathrm{cm}^{2}$ to $136.25 \times \mathbf{1 0}^{-3} \mathrm{emu} / \mathrm{cm}^{2}$. So it is concluded that thin films prepared at high temperature $\left(90^{\circ} \mathrm{C}\right)$ exhibit higher values of saturation magnetization. A low coercivity is an essential character required for $\mathrm{Ni}$ based thin films. Grain size of the film plays a vital role in deciding coercivity of 
RASĀYAN $J$. Chem.

Vol. 10 | No. 3 |744 - 750 | July - September | 2017

thin film. If grain size is large, the properties of ferromagnetic materials are decided based on the domain wall movement. By reducing the grain size, magnetic properties of thin films can be changed. If grain size is in the range of nanometres, coercivity of magnetic materials is decreased. Coercivity of the films is also affected by other aspects such as impurities, film stress etc.

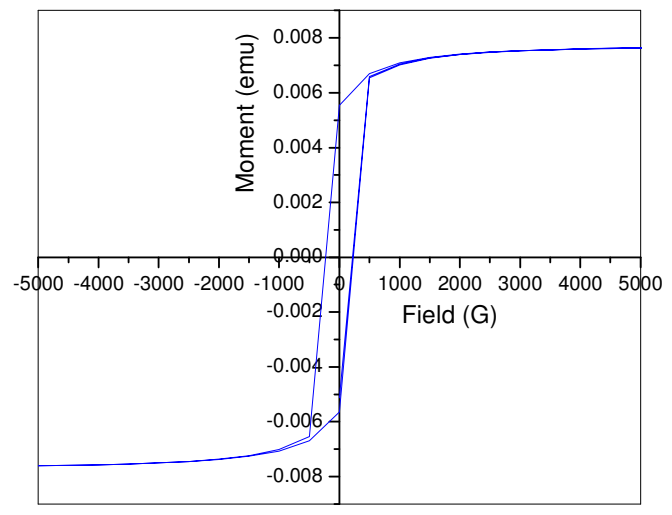

(a)

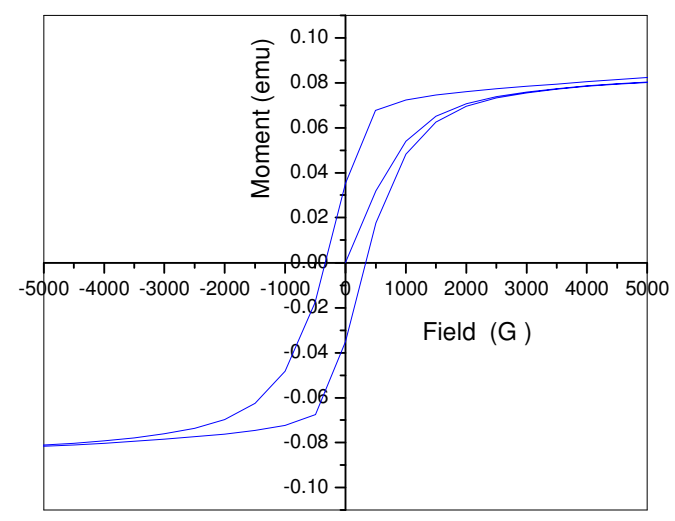

(c)

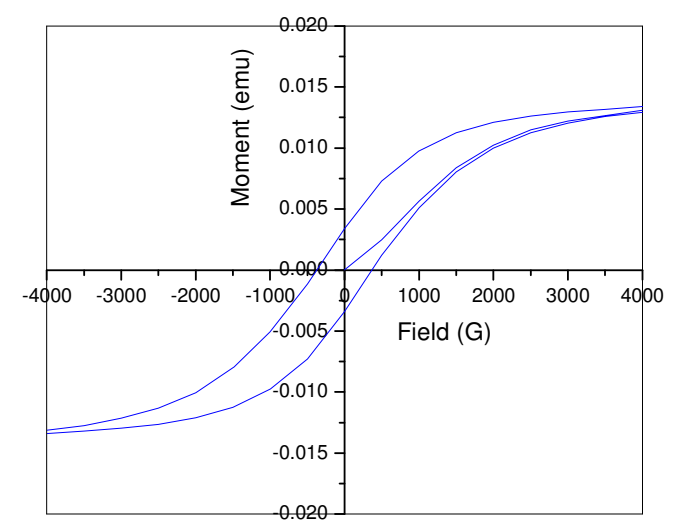

(b)

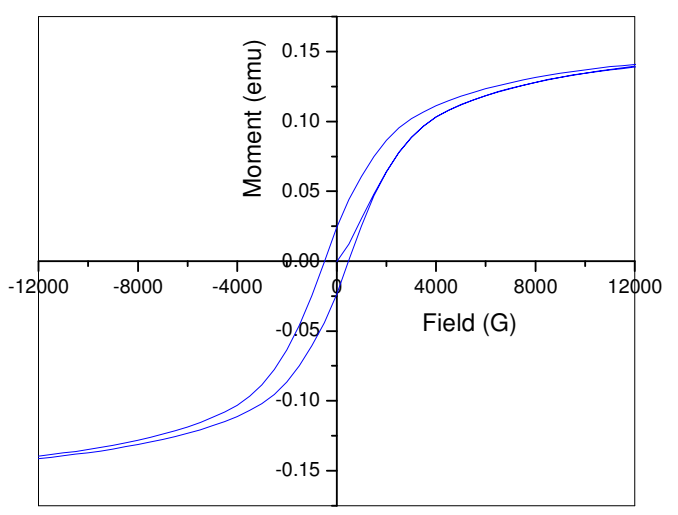

(d)

Fig.-5: Magnetic Hysteresis loops of Ni-Fe-S thin film at bath temperatures (a) $30^{\circ} \mathrm{C}$ (b) $50^{\circ} \mathrm{C}$ (c) $70^{\circ} \mathrm{C}$ (d) $90^{\circ} \mathrm{C}$

Thin film stress is reduced because of temperature increases. Due to smaller crystalline size and low stress during formation of $\mathrm{Ni}-\mathrm{Fe}-\mathrm{S}$ thin films at $90^{\circ} \mathrm{C}$ have higher saturation magnetization. By analyzing VSM results, it is concluded that the best soft magnetic thin films are obtained at high temperatures.

\section{CONCLUSION}

Electroplated Ni-Fe-S nanocrystalline thin films have been successfully coated on the copper substrate. The structural, mechanical and magnetic behaviors of Ni-Fe-S alloy thin films are analyzed. The result shows that the electroplated Ni-Fe-S alloy films have an average crystalline size of $26 \mathrm{~nm}$ and the films have FCC structure with three diffraction peaks. The thin films obtained at different temperatures are uniform, bright and crack free. While increasing the bath temperature from $30^{\circ} \mathrm{C}$ to $90^{\circ} \mathrm{C}$, the Ni content of Ni-Fe-S thin increases and the Fe content decreases. The Ni-Fe-S thin films have good adherence with the substrate and Vickers hardness of the film is high as $191 \mathrm{VHN}$ at $90^{\circ} \mathrm{C}$. The Ni-Fe-S thin films coated at room temperature $\left(30^{\circ} \mathrm{C}\right)$ have a coercivity of 241.32 Gauss with saturation magnetization value of $7.327 \times 10^{-3} \mathrm{emu} / \mathrm{cm}^{2}$. 
RASĀYAN J. Chem.

Vol. 10 | No. 3 |744 - 750 | July - September | 2017

\section{REFERENCES}

1. V. Nosang, D.Y. Park, B.Y. Yoob and T.A. Paulo, Journal of Magnetism and Magnetic Materials, 265, 189(2003).

2. S. Iwasaki and Y. Nakamura, Journal of Magnetism and Magnetic Materials, 200, 634(1977).

3. H. J. Cho, S. Bhansali and C. H. Ahn, Journal of Applied Physics, 87, 6340(2000).

4. R. Celine and F. Patrick, Journal of Mater. Sci., 46, 6046(2011).

5. M. Ghorbani, A. G. Dolati and A. A. Afshar, Rus. J. Electrochem., 38, 1173(2002).

6. K. Baonkeup and Y. Bongyoung, Surf. Coat. Technol., 205, 740(2010).

7. X.H. Yan, J.Q. Sun, Y.W. Wang and J.F. Yang, Journal of Molecular Catalysis A: Chemical, 252, 17(2006)

8. N. Sulztanu and J. Fbrinza, J. Optoelectron Adv. Mat., 6, 641(2004).

9. M. Bedir, O.F. Bakkaloglu, I.H. Karahan and M. Oztas, Pramana, 66(6), 1093(2006).

10. R.Kannan, S. Ganesan and T.M. Selvakumari, Digest Journal of Nanomaterials and Biostructures, 7, 1039(2012).

11. S.L. Wang, Surface and Coatings Technology, 186, 372(2004).

12. S. Sam, G. Manavalan, A. Guittoum, N. Gabouze and S. Djebbar, Surf. Sci., 601, 4270 (2007).

13. M.Watanable, T. Nakayama, K. Watanable, T. Hirayama and A. T. Onomura, Materials Transactions, 37, 489(1996).

14. G.V. Fernandez, P.J. Grundy and M.M. Vopson, J. Phys, Condens. Matter, 1(1), 6(2013).

15. R. Balachandran, H.K. Yow, B.H. Ong, K.B. Tan, K. Anuar and H.Y. Wong, Int. J. Electrochem. Sci., 32, 3564(2011).

16. N. Myung, Bull. Korean Chem. Soc., 22, 994 (2001).

17. I. Giouroudi, A. Ktena, and E. Hristoforou, J. Optoelectron. Adv. Mat., 6 ,661(2004).

18. P. Esther and C. Joseph Kennady, Journal of Non Oxide Glasses, 1, 35(2010).

19. S. Tabakovic, V. Riemer, Vas'ko, V. Sapozhnikov, and M. Kief, J. Electrochem. Soc., 150, 635(2003).

20. H. Li, H.X. Li, W.L. Dai, W.J. Wang, Z.G. Fang and J.F. Deng, Applied Surface Science, 152 25(1999).

21. R. Kannan , S. Ganesan and T.M. Selvakumari, Optoelectronics and Advanced Materials-Rapid Communication, 3-4, 383(2012).

22. X. F. Meng, D.H. Li, X.Q. Shen and W. Liu, Applied Surface Science, 256, 3753(2010).

23. Z.G. An, J.J. Zhang and S.L. Pan, Applied Surface Science, 255, 2219(2008).

24. Y.J. Li, R. Wang, F.M. Qi and C.M. Wang, Applied Surface Science, 254, 4708(2008).

25. R. N. Emerson, C.J. Kennady and S. Ganesan, Thin Solid Films, ,515, 3391(2007).

[RJC-1758/2017] 